\title{
0 estado de direito no idealismo alemão: Kant, Fichte, Hegel
}

\author{
Jean-François Kervegan \\ Universite Pantheon-Sorbonne, Paris \\ kervegan@univ-paris1.fr
}

resumo Esse artigo busca mostrar, em contraste com uma tradição já estabelecida, que a filosofia clássica alemã, longe de fazer do indivíduo simples apêndice do Estado, propõe uma verdadeira teoria do Estado de direito <Rechtsstaat $>$, e isso, antes mesmo que esta tenha sido formulada pelos juristas liberais. Mas se trata de uma teoria crítica, que põe em evidência o caráter ilusório da idéia liberal segundo a qual a sociedade civil poderia furtarse inteiramente à tutela do Estado. Para Fichte e para Hegel, mas também para Kant, apenas um Estado verdadeiro, com os atributos de sua potência, pode ser um verdadeiro Estado de Direito.

palavras-chave Fichte; Kant; Hegel; sociedade civil; liberalismo; Estado de direito $<$ Rechtsstaat>

À primeira vista parece surpreendente procurar as premissas da problemática futura do Estado de direito, tal como ela se elabora a partir de Robert von Mohl, no que se convencionou nomear de idealismo alemão. Limitar-se-á aqui às obras de Kant, Fichte e Hegel, mas poder-seia estender o campo de estudo a certos escritos de Humboldt, de Schelling ${ }^{1}$ ou de Reinhold, sem falar de numerosos juristas que reclamam para si o kantismo, aos quais Fichte ridicularizará2 ${ }^{2}$ Com efeito, se é verdade que o Rechtsstaat foi concebido como uma resposta polêmica ao Polizeistaat, ao Estado de polícia do absolutismo esclarecido, e como uma alternativa ao Machtstaat glorificado por Treitschke e construído por Bismarck, haveria boas razões, parece, para contar esses filósofos no

Recebido em 20 de outubro de 2006. Aceito em 20 de dezembro de 2006.

Tradução:Vivianne de Castilho Moreira. Revisão: Paulo Vieira Neto e Vinicius de Figueiredo. doispontos, Curitiba, São Carlos, vol. 4, n. 1, p. 107-135, abril, 2007 
número dos seus adversários. Acaso não é Kant um partidário do absolutismo esclarecido, Fichte um adepto do Estado policial e um entusiasta do nacionalismo pangermanista? O sistema de Hegel acaso não é, segundo Rudolf Haym, "a morada científica do espírito da restauração prussiana" (HAYM, 1857, p. 359)? Tal é ao menos a maneira como esses pensadores são, ainda nos nossos dias, comumente percebidos ${ }^{3}$. De outra parte, bem parece, numa primeira consideração, que as raízes dessa doutrina sem dúvida tipicamente alemã — a teoria do Estado de direito devem ser procuradas antes em outras direções, fora do contexto puramente alemão. A saber: no constitucionalismo anglo-saxão, por um lado, em certas correntes do pensamento francês, por outro.

O que justifica, todavia, que se procure aquelas raízes no contexto alemão consiste, primeiramente, no fato - que buscar-se-á aqui estabelecer - de o pensamento jurídico e político dos filósofos em questão estar muito distante da imagem caricatural que por vezes lhe é atribuída. Em segundo lugar, tal justificativa passa pelo fato de que esses pensadores forjaram, em uma ótica puramente especulativa, instrumentos conceituais dos quais as doutrinas do Estado de direito vão se apropriar e traduzir em reivindicações jurídicas e políticas: é o caso, por exemplo, da distinão entre Staat e Gesellschaft, entre Estado e sociedade (civil), distinção esta que Hegel seráp o primeiro a desenvolver de maneira sistemática, mas que encontra notáveis antecedentes precisamente em Fichte e Kant. Mas é também o caso de todo um conjunto de temas que traduzem com certeza o impacto do pensamento inglês e da Revolução francesa sobre a filosofia alemã do fim do século XVIII e do início do XIX, ao mesmo tempo em que são testemunos também da inventividade própria de Kant e de seus sucessores. O aprofundamento do tema da separação dos poderes, a insistência sobre os direitos fundamentais (acompanhada, nesses pensadores, de uma suspeita em relação a sua apresentação comum) e sobre o primado da lei, a importância conferida à representação política, a idéia segundo a qual a ordem jurídica tem uma consistência independente da existência de instituições políticas particulares são aspectos pelos quais "o idealismo alemão" prepara o terreno à problemática do Estado de direito sob sua figura propriamente alemã. Parece assim legítimo e fecundo, como diz O. Jouanjan, "interrogar o sentido do constitutionalismo (...) a partir do idealismo alemão" (JOUANJAN, 1998, p. 280). Nós 
examinaremos então de modo não exaustivo os pontos sobre os quais esses filósofos podem ser observados como precursores da doutrina liberal do Rechtsstaat, sem todavia mascarar o que os distancia dela.

\section{Fichte}

Há ao menos duas razões para romper aqui com a cronologia e com a apresentação habitual evocando Fichte, o discípulo rebelde, antes de Kant, o mestre. A primeira reside na seguinte: se Kant, incontestavelmente, e Hegel em certos pontos, podem ser legitimamente considerados como precursores da doutrina alemã do Rechtsstaat, é mais dificil dizer o mesmo de Fichte, freqüentemente visto por seus contemporâneos, e mais ainda pela posteridade, como um partidário de um Estado policial e liberticida; o próprio Hegel, tão freqüentemente apresentado como zelador de um Estado onipontente e divinizado, deu crédito a essa suspeita reprovando a Fichte ter sugerido que o Estado torne obrigação para seus cidadãos estar permanentemente em posse de um documento de identidade guarnecido, para os mais notáveis dentre eles, de um retrato (cf. FICHTE, 1984, p. 304 e HEGEL, 2003, p. 105)! Aliás, é bem conhecido que Fichte rejeita a separação dos poderes, e considera a administração da justiça, e também a da polícia, como função do executivo (FICHTE, 1984, p. 174). O Estado fichteano, que se apresenta ele próprio como um Estado de coerção (cf. FICHTE, 1990, Lição 10, p. 156), dificilmente pode, à primeira vista, ser considerado como um Estado de direito, e se situa, incontestavelmente, no limite do nosso propósito. Segunda razão para essa guinada: se Fichte é um discípulo de Kant confesso mas recalcitrante, ocorre que no curso dos anos 1790 ele regularmente o precedeu, de sorte que se pode considerar que, no domínio jurídico e político, é o mestre que segue, por vezes com dificuldade, o discípulo. Todavia, se não se trata de colocar Fichte em meio aos precursores da doutrina do Estado de direito, sem dúvida não é porque seu pensamento fosse hostil à liberdade em geral, à liberdade política em particular. É bem sabido, ao contrário, que Fichte reivindica o mérito de ter concebido "o primeiro sistema da liberdade" (Carta a Baggesen, abril de 1795, apud: LEON, 1922, t. II, p. 68). Em contrapartida, é certo que, 
em proveito de um republicanismo que deve muito ao modelo da França revolucionária, Fichte - o "primeiro" Fichte seguramente, mas os outros também... ${ }^{4}$ - recusa a concepção liberal da liberdade da qual são solidárias as teorias do Estado de Direito (seria sem dúvida preciso nuançar e sobretudo precisar esta afirmação). Isso posto, pode-se, assinalar em sua obra vários temas que abrem indiretamente a via à idéia de Rechtsstaat. Com efeito, eles sustentam uma relativização do político que é, sabe-se desde Locke e Constant, o eixo portador das convicções liberais, conferindo ao Estado um papel maior na realização dos princípios do direito, princípios que todavia tendem à limitação de seu papel.

Um primeiro aspecto fundamental dessa abertura se encontrará em Kant e, evidentemente, em Hegel, consistindo na recusa em confundir a sociedade $<$ Gesellschaft $>$ e o Estado $<$ Staat $>$, quer dizer, a recusa de apreender o vínculo social em termos que seriam exclusivamente, ou mesmo, preferencialmente políticos. No escrito de 1793 sobre a Revolução Francesa, esta recusa inscreve-se em um percurso radicalmente individualista e que se poderia dizer libertário. Fichte, com efeito, não se contenta em distinguir entre a sociedade jurídica em geral - a sociedade tal como se fez possível pela existência ou a postulação de uma ordem jurídica em geral, da ordem do direito privado - e a sociedade civil ou política propriamente dita, fundada sobre o contrato social, ou, dito de outro modo, sobre o Estado $^{5}$. Ele distingue também desses dois tipos de sociedade, que supõem um e outro uma "relação moral", no caso aquela de "direitos e deveres recíprocos", uma sociedade que é pura e simples coexistência física de indivíduos, sem a menor dimensão jurídica; e é de se deplorar que se esquece muito facilmente esse sentido, logicamente primeiro, da palavra sociedade (ver FICHTE, 1989, p. 146). Daí resulta uma representação estratificada das relações possíveis entre seres racionais, que Fichte simboliza por um conjunto de círculos concêntricos: o domínio da consciência moral <Gewissen $>$; do direito natural; dos contratos em geral (dito de outro modo, do direito privado), enfim, o do contrato civil < bürgerlicher Vertrag>, ou, em outros termos, do Estado político. $\mathrm{O}$ objetivo dessas distinções reside não somente em fundar um direito de insubordinação e de insurreição coletivo, mas também em proclamar a revocabilidade permanente do contrato social por cada contratante ${ }^{6}$. Porém, sem considerar essas conseqüências extremas, ainda 
que de modo algum fortuitas, resulta uma limitação de princípio dos direitos ou das competências <Befugnisse $>$ do Estado: é de maneira ilegítima que ele "procura invadir o campo dos contratos em geral, aquele mesmo do direito natural e, se aprouver a Deus, até aquele da consciência [moral]"7. Nem o direito privado nem o direito natural, nem a norma moral pressupõem o Estado; nem o homem, nem a pessoa, nem o sujeito moral pressupõem o cidadão e menos ainda o soberano.

Em seus escritos ulteriores, Fichte retifica sem dúvida a orientação libertária das Considerações sobre a revolução francesa; mas o que subsiste delas é a rejeição de toda compreensão imediata e puramente política do vínculo social. Assim, as Conferências sobre a destinação do sábio (1794) retomam a distinção entre a sociedade e o Estado, mas de um ponto de vista totalmente diferente, que anuncia aquele do Fundamento do direito natural. Doravante, Fichte considera que "o homem tem a obrigação de viver em sociedade", embora isso nem sempre implique uma necessidade do Estado, pois este não é senão uma "espécie particular de sociedade empiricamente condicionada" (FICHTE, 2003, p. 48-49). Isso desemboca sobre uma temática que vai ocupar um lugar na reflexão jurídica e política de Fichte: aquela do Notstaat, do Estado de calamidade < détresse > ou de necessidade. O Estado implica a instituição da coação (que é, claro, coisa bem diferente da violência) nas relações sociais, ele nem mesmo tem outra destinação, todavia é em vista de um fim que o ultrapassa e cuja realização o tornará supérfluo: aquele de uma "sociedade perfeita", de sorte que "é o objetivo de todo governo tornar o governo supérfluo" (FICHTE, 2003, p. 49). Daí para frente, a perspectiva difere daquela de 1793, e é ela que vão consolidar os escritos de filosofia jurídica, assim como aqueles que concernem à filosofia da história: o Estado, instituição de calamidade, visa à sua própria supressão, ou, ao menos, ele se encaminha para um contexto de racionalidade do qual é, de início, como negação em ato. Não tendendo a nada outro que provocar e impor um respeito absoluto ao direito ${ }^{8}$ — porém em nenhum caso das obrigações morais - ele se faz, então, essencial ao propósito fichteano de separar rigorosamente essas duas esferas de normatividade, bem mais ainda que na metafisica dos costumes kantiana. O Estado tem o objetivo delimitado de impôr às vontades individuais reticentes à constituição de um estado (sem maiúscula) de direito, quer dizer, de um rechtlicher Zustand cuja 
função, antes de tudo, reside em garantir a liberdade civil e pessoal (ver esp. FICHTE, 1990, p. 169 et 196 e 1984, p. 144-145). Todavia, o estado não poderia ultrapassar esse objetivo sem ir ao encontro de sua própria destinação, que é realizar "o fim da razão", ainda que em um campo cuidadosamente circunscrito:

A promoção refletida do fim da razão pelo Estado se estende até aí [assegurar uma total segurança interior e exterior] e não além (...) Os ramos superiores da cultura da razão: a religião, a ciência, a virtude, jamais podem se tornar o fim do Estado (FICHTE, 1990, p. 175).

Em resumo, o Notstaat, o Estado de necessidade que se constitui ao longo da terceira época da história da humanidade, o "estado do pecado consumado" (FICHTE, 1990, p. 28), não consiste senão na "primeira condição do progresso gradual em direção a um Estado conforme à razão e ao direito" (FICHTE, 1986, p. 227), o qual se realizará na penúltima época, a "idade da ciência da razão". Que será este Estado plenamente racional, e em que medida se abrirá à sua própria extinção, tendo consumado a missão que é a sua (impor o reino do direito, educar os cidadãos nesse sentido), é o que não fica totalmente claro, e as posições de Fichte quanto a isso parecem variar de um texto para outro 9 . Uma coisa, todavia, é certa: Fichte fixa limites muito estritos para a instituição política e mesmo para o direito, dela inseparável, tal como os liberais, sem prejuízo de tudo o que o opõe a eles, no que diz respeito a sua visão da organização do Estado (mais ainda: há no liberalismo alemão, e precisamente nos doutrinários do Estado de direito, aspectos incontestavelmente autoritários). Estes últimos definem uma esfera inviolável de liberdade e de independência individuais, que Fichte denomina "propriedade absoluta" (FICHTE, 1984 p. 250 ss.), na qual o Estado não tem "nenhum direito de intervir" (FICHTE, 1984 p. 255). Essa propriedade, que recobre o domicílio e o conjunto dos bens não sujeitos ao imposto, quer dizer, de tudo o que não é um produto da natureza, nem um objeto fabricado por $\operatorname{mim}^{10}$, possui uma inviolabilidade tal que é preciso toda uma argumentação para justificar o fato de a polícia poder adentrar em minha casa quando um malfeitor aí se introduziu e ameaça minha vida...

Pode-se espantar-se dessa importância conferida à propriedade privada individual por um autor de bom grado considerado como um precur- 
sor do socialismo autoritário. Mas ela não é contestável; ela é mesmo nodal. Para o autor do Fundamento do direito natural, os direitos originários (os "direitos do homem") são ficções necessárias que enunciam as condições mesmas da personalidade, sem a qual é impossível a um indivíduo pretender fazer parte de qualquer comunidade. Ora, a propriedade é o cerne desses direitos que, do ponto de vista da livre especulação, não devem nada à instituição da sociedade: ela é, em linguagem corrente, um direito inalienável e imprescritível (FICHTE, 1984, p. 132). Nessas condições, não é então surpreendente que o "contrato de propriedade", nos termos do qual "cada indivíduo concorda com todos sobre a propriedade, os direitos e a liberdade que ele deve ter, e sobre aqueles que ele deve deixar aos outros" (FICHTE, 1984, p. 207), seja a peça fundamental da complicada arquitetura do contrato social, tal como o apresenta Fichte (seus outros elementos são o contrato de proteção e o contrato de união): a instituição de uma regra universal de discriminação do seu e do meu, sem a qual não há "relação jurídica" possível entre os contratantes. Encontra-se aqui, expressa com uma clara consciência das conseqüências que ela comporta, uma tese já presente nas Considerações sobre a revolução francesa: a anterioridade lógica não somente dos direitos "naturais", mas também do direito privado em geral (da "esfera dos contratos", segundo o vocabulário do texto de 1793) em relação ao direito público e a seus objetos, dos quais está em primeiro plano o Estado. Eis por que a legislação civil, se ela tem evidentemente o Estado como condição efetiva, tem por único princípio o "contrato de propriedade" (FICHTE, 1984, p. 221), que é um contrato passado de indivíduo a indivíduo, ou antes entre cada indivíduo e a totalidade distributiva dos outros. Se é verdade que é próprio do liberalismo considerar o político como um meio a serviço dos fins individuais, então parece difícil não considerar esse momento da argumentação de Fichte como liberal, e não será espantoso encontrar nele traços que não desmentem um Locke - que ele certamente leu com atenção - e até um teórico do Estado mínimo:

Com respeito àquilo pelo que o indivíduo não contribui ao que o

Estado projeta, ele é totalmente livre; deste ponto de vista, ele não é integrado ao todo que é o corpo do Estado, mas permanece ao contrário um indivíduo, uma pessoa livre, não dependendo senão de si mesma (FICHTE, 1984, p. 217). 
Mas isso não é certamente senão um momento da argumentação, e a obrigação política (traduzida pelo contrato de proteção) é o complemento necessário da autonomia da pessoa. Ora, ela implica conseqüências muito pouco liberais. No que concerne à "propriedade de cidadão", distinta da propriedade absoluta, o Estado exerce um direito de vigilância e uma ação de redistribuição, conformemente a uma dupla máxima: "não deve haver pobres" e, reciprocamente," não deve haver desocupados" (FICHTE, 1984, p. 225)! Para dizê-lo de maneira simplista: se, no que concerne ao patrimônio, Fichte se mostra um liberal severo, ele é, no que concerne aos ganhos, um socialista conseqüente. Tal é o sentido da tese segundo a qual, com o contrato instituindo uma lei de coerção, "o próprio Estado se torna estado de natureza do homem" (FICHTE, 1984, p. 163).

Um último ponto permanece a evocar a fim de situar exatamente Fichte em relação aos teóricos do Estado de direito: a questão da organização dos poderes. Se se segue Carl Schmitt (mas igualmente Kant), os princípios do Estado de direito "burguês", que derivam um e outro da representação liberal da liberdade, são dois em número. Um é o princípio de repartição, delimitando a esfera do indivíduo, segundo o qual toda ingerência do Estado torna-se, se não impossível, ao menos estritamente controlada (teoria da reserva da lei); o outro consiste em um princípio de organização que divide e especifica as competências dos diferentes ramos da atividade do Estado. Em outros termos, "direitos fundamentais e separação dos poderes caracterizam o conteúdo essencial" de um Rechtsstaat (SCHMITT, 1993, p. 265). Como isso se dá em Fichte ? Sobre o primeiro ponto, como foi visto, suas posições são heterodoxas. Se ele subscreve o princípio da repartição no que concerne ao que ele nomeia a "propriedade eabsoluta" - expressão que fala por si mesma - ele o recusa no que concerne à propriedade cidadã, quer dizer, para os ganhos do patrimônio e do trabalho. Sobre o segundo ponto, em contrapartida, suas posições são muito pouco liberais. Contrariamente a Kant, ele rejeita a separação ou mesmo a divisão dos poderes no sentido que o termo tem desde o fim do século XVIII. A separação entre o legislativo e o executivo repousa sobre uma confusão de linguagem, visto que uma comunidade humana não tem, no fundo, senão uma só lei, aquela que proclama "a vontade de viver em comum conformemente ao direito" 
(FICHTE, 1984, p. 174), e que as leis no sentido usual do termo não são em realidade senão "decretos" de aplicação dessa lei fundamental da qual os detentores do poder político (os representantes do povo: cf. FICHTE, 1984, p. 173) são os executores, mas não os autores. Aliás, a separação entre o executivo e o judiciário, de que ordinariamente se faz a pedra de toque do constitucionalismo, não é "possível senão em aparência" (FICHTE, 1984, p. 175). No fundo não há, portanto, senão um poder no seio do Estado: aquele de executar a única lei jurídica que enuncia as condições de uma coexistência racional de seres livres. Até este ponto, Fichte está na antípoda do princípio rechtsstaatlich da separação dos poderes, que ele contexta ainda mais radicalmente que Hegel. Todavia, é para reintroduzir imediatamente sob uma forma que suscitou o espanto divertido de seus contemporâneos (cf. HEGEL, 2003, \ 273 Obs., p. 367368), mas que, no exame, revela-se espantosamente moderna: ele proclama, com efeito, a necessária separação entre o poder executivo (isto é, político-judiciário) e o do que ele denomina o eforado, poder encarregado "de controlar e de julgar como esse poder executivo é administrado" (FICHTE, 1984, p. 174). Ora, as explicações oferecidas sobre este ponto mostram sem ambigüidade que, por assim dizer, trata-se de uma côrte constitucional tendo o poder de suspender as decisões das autoridades políticas (legislativas, administrativas, bem como judiciárias), eventualmente de destituir estas últimas e, em todo caso, de apelar ao povo constituinte, à comunidade soberana, mesmo quando esta já estava dissolvida, após o ato de instituição do poder constituído. Mas, bem evidentemente, as competências dessa instância de impeachment são extraordinariamente estendidas, visto que, na sociedade civil e política, a fronteira entre o privado e o público torna-se inassinalável. O eforado desempenha assim o papel que desempeha na França atual tanto o Conselho constitucional quanto o Conselho de Estado e da Corte de Cassação, ao mesmo tempo que ele é a Alta Côrte de Justiça da República. Mas esta comparação é igualmente falsa, visto que os éforos de Fichte não são juízes, são antes promotores públicos investidos do poder de prender-se a si próprios e de citar o conjunto das autoridades constituídas diante do único tribunal que é a própria sociedade. Definitivamente, o eforado não é outra coisa que a tradução institucional do caráter constantemente revogável das "instituições sociais" quando não se alcançou seu fim -

doispontos, Curitiba, São Carlos, vol. 4, n. 1, p. 107-135, abril, 2007 
expressão da igualdade de todos no direito. Teriam os teóricos do Estado de direito aceito um tal radicalismo, evidentemente portador de conseqüências eventualmente subversivas? É pouco provável.

\section{Kant}

Se a situação de Fichte com respeito à problemática do Estado de direito é dificil de definir, a de Kant é muito menos. Partidários e adversários da doutrina concordam em ver nele um de seus precursores diretos ${ }^{11}$. Como se sabe, os escritos kantianos dos anos 1790 , evidentemente marcados pela experiência da Revolução francesa, da qual o autor é um espectador engajado, elaboram uma definição do que Teoria e prática nomeia "a condição civil, considerada simplesmente como condição jurídica" (KANT, 2003, p. 30) e o escrito sobre a Paz perpétua (1795) batiza sem rodeios de "constituição republicana" (KANT, 1974, p. 91). Três passagens paralelas contidas nos dois opúsculos supracitados e, por último, na Rechtslehre (1796), expõem os princípios do que se pode chamar, a título de justificação, o Estado de direito kantiano. Esses princípios, diz-nos Kant, são menos "leis do Estado já erigido" (leis positivas, portanto) que "leis segundo as quais é possível erigir um Estado" (KANT, 2003, p. 31). Eles são então as condições universalmente racionais da instituição política, únicas conformes ao direito humano $<$ Menschenrecht $>$, normas jurídicas fundamentais a que deve satisfazer um Estado para ser autêntico, quer dizer, uma república no sentido kantiano do termo. Em conjunto, eles desenham os traços do que Kant denomina "Estado segundo a idéia" ou ainda respublica noumenon, distinguindo esta das diversas formas possíveis de respublica phaenomenon ${ }^{12}$. Esses princípios, seguindo a exposição mais antiga e mais detalhada, aquela de Teoria e prática ${ }^{13}$, são esses:

a) a liberdade de cada membro da sociedade (o texto alemão diz Sozietät e não Gesellschaft, o que não é talvez indiferente, se se lembra que este último vocábulo não qualifica somente a sociedade civil ou política, mas todas as formas de comunidade que podem existir mesmo em um estado de natureza; cf. KANT, 2003b, $\ 41$, p. 188) enquanto ser humano < Mensch>;

b) a igualdade de cada um com cada um enquanto súdito <Untertan, subditus $>$ do soberano. A Rechtslehre diz algo semelhante, de maneira à 
primeira vista diferente: quando apresenta a igualdade civil consistindo em "não reconhecer no povo outro superior que aquele que se tem a faculdade moral de ligar juridicamente, do mesmo modo que ele pode nos ligar» (KANT, 2003b, \46, p. 196). O texto de 1795 diz mais claramente ainda: a igualdade dos membros da sociedade enquanto cidadãos;

c) a dependência de cada membro da comunidade, enquanto cidadão <Bürger>. A Paz perpétua diz: "a dependência de todos em relação a uma única legislação comum". A Doutrina do direito modifica esta terceira condição que é doravante "a independência civil", esta consistindo em "não dever sua existência e sua conservação senão a seus próprios direitos e a suas próprias forças, e não ao arbítrio de um outro". A substituição não é negligenciável: trocando o princípio da dependência em relação à lei pelo da "personalidade civil" (KANT, 2003b, \ 46, p. 196), Kant mostra-se mais explicitamente atento ao que se pode nomear o enraizamento social do Estado de direito, o que traduz, paralelamente, a apropriação da distinção que faz Sieyès entre cidadania ativa e passiva (SIEYÈS, 1988, p. $600)^{14}$. Acaso não há nessa aceitação de uma discriminação entre os cidadãos uma contravenção ao primeiro princípio (liberdade) e sobretudo ao segundo (igualdade)? Não, pois a liberdade e a igualdade civis são somente as condições por assim dizer formais de uma constituição jurídica da sociedade política. Todos os Bürger - é preciso compreender: todos os cidadãos enquanto cidadãos passivos - são livres (eles têm a personalidade jurídica: nada de escravidão, de servidão ou de capitis deminutio, ao menos para os adultos de sexo masculino e sãos de espírito) e iguais perante a lei e sob a autoridade do soberano. Mas nem todos eles são "co-legisladores"15, quer dizer, eleitores: só podem, com efeito, participar da formação da lei (elegendo representantes) aqueles que gozam de uma independência não apenas jurídica, mas igualmente social e econômica, a qual deve oferecer a garantia da independência do julgamento e do sufrágio. Pode-se pensar o que se quiser do argumento, que fará fortuna entre os liberais do século XIX; sempre é ele que parece corresponder bem à ótica "burguesa" que é aquela dos teóricos do Estado de direito.

Convém notar que o primeiro desses princípios (a liberdade civil) se beneficia do que Rawls nomeia uma "prioridade lexical" em relação aos outros dois, visto que esses últimos só podem ter efetividade se ele é integralmente satisfeito: a liberdade pessoal é para Kant, como para os

doispontos, Curitiba, São Carlos, vol. 4, n. 1, p. 107-135, abril, 2007 
autores da Declaração de 1789 , a uma só vez o primeiro dos direitos do homem (artigo 2) e a condição geradora de todos esses direitos (artigo 1). Aliás, deve-se sublinhar que o primeiro princípio, ao menos tal como é formulado no opúsculo de 1793, é independente da existência ou não de uma "sociedade civil" no sentido que Kant continua a dar a esse termo, quer dizer, de um Estado ou de uma sociedade política. A propósito, é preciso lembrar que para Kant o estado de natureza, quer dizer, a ausência de uma constituição "civil" (política), não é incompatível com a existência de formas de sociabilidade. $O$ contrário do estado de natureza não é o estado social, mas o estado civil, em outros termos, a presença de uma sociedade política fundada sobre princípios jurídicos e que administra publicamente o direito, de sorte que, em um hipotético estado de natureza, pode haver sociedades jurídicas < rechtsmässige Gesellschaften> mas não rechtlicher Zustand, estado de direito no sentido de reino do direito assegurado pela "garantia social" (outro conceito de Sieyès que se deixa de bom grado inserir em um contexto kantiano) ${ }^{16}$. Em resumo, o direito, em seu princípio como em suas realizações primeiras, não pressupõe o Estado; é o Estado, ao contrário, que pressupõe o direito, no qual ele encontra seu fundamento, e que, em contrapartida, garante sua boa administração.

Contudo, o princípio da liberdade não é (assim como, de resto, os dois outros) um simples princípio "abstrato" de direito natural, pois ele não pode ser efetivamente satisfeito" senão quando os indivíduos forem juridicamente livres e iguais ». As pessoas jurídicas constituem uma sociedade civil ou política e se colocam como cidadãos:

"pode-se dizer do estado jurídico < rechtlicher Zustand> que todos os homens que podem se encontrar (mesmo involuntariamente) em relações de direito devem nele entrar" (KANT, 2003b, \41, p. 188).

Nessas condições o primeiro princípio kantiano aparece como um princípio de restrição ou de delimitação do Estado, visto que não pressupõe a existência da sociedade política, mas a implica como a garantia de sua efetividade: ele inscreve-se totalmente no esquema do "princípio de repartição", como o nomeia Schmitt, visto que ele conduz a uma separação entre esfera pública e esfera privada. Ele exclui com efeito toda forma de gestão coletiva ou comunitária do bem privado, tome ela a 
forma do Estado de polícia do despotismo esclarecido ou do futuro Estado social. Donde a firme rejeição do que Kant denomina o "princípio da benevolência" < Prinzip des Wohlwollens>:

"Um governo que seria fundado sobre o princípio da benevolência em relação ao povo, tal como o do pai sobre seus filhos, quer dizer, um governo paternal em que os súditos, tais como crianças menores incapazes de decidir sobre o que lhes é verdadeiramente útil ou prejudicial, são obrigados a se comportar unicamente de maneira passiva, a fim de esperar unicamente do julgamento do chefe do Estado a maneira como eles devem ser felizes, e unicamente de sua bondade, que ele igualmente o queira, um tal governo é o maior despotismo que se pode conceber (uma constitução que suprime toda liberdade dos súditos que então não têm mais nenhum direito)"17.

Por conseguinte, é preciso considerar que o princípio de liberdade dado que, como foi lembrado, a pertença a uma comunidade política é considerada por Kant como um imperativo jurídico, se não mesmo como um imperativo ético, como um "dever de virtude" - é uma metanorma que se aplica obrigatoriamente à sociedade política, que deve observá-lo para ser conforme ao direito, quer dizer, para ser uma república, mas cuja validade é independente da existência desta e, evidentemente, das formas de sua organização.

As disposições constitucionais que permitem satisfazer aos três princípios são definidas de maneira precisa no escrito sobre a paz perpétua (KANT, 1974, p. 95-97). Nele, Kant enuncia dois critérios de identificação da "consituição republicana". No que concerne ao "modo de governo", que é, no julgamento de Kant, mais decisivo que a "forma da soberania", quer dizer, que o regime político, o critério fundamental é a separação dos poderes, e mais precisamente aquela entre o executivo e o legislativo. Sabe-se a este respeito que, para Kant como para Locke, só o legislador é soberano, e que esse soberano "não pode ser senão o próprio povo unido" (KANT, 2003b, \47, p. 198 ; cf. $\$ 46$, p. 196), enquanto o "regente" (o chefe do Estado) nada mais é senão o chefe do executivo (KANT, 2003b, $\ 49$, p. 199). Em uma tal perspectiva, vê-se que a monarquia constitucional não é de modo algum incompatível com a aceitação, sob certas reservas, do princípio da soberania popular. O segundo critério 
do "republicanismo", no sentido kantiano, consiste no caráter representativo do exercício dos poderes executivo $e-$ mas a coisa não é clara legislativo. Donde a tese: "toda forma de governo que não é representativa não é uma forma [de governo] propriamente falando"18. É este segundo critério que justifica a exclusão da democracia - bem entendido, da democracia "pura", da democracia "direta" - que exclui a representação, bem como viola forçosamente o princípio da separação dos poderes.

Todavia, o que parece ainda mais importante que esses dois critérios é a afirmação, feita não obstante como que de passagem, segundo a qual o modo de governo $<$ Regierungsart $>$ é, para o povo, quer dizer aqui, para os súditos < sujets> "sem comparação" mais importante que a forma do Estado ou o regime < Staatsform $>$ (KANT, 1974, p. 97). Encontra-se aqui uma primeira expressão do que virá a ser um dos eixos da doutrina do Rechtsstaat, aquele que enuncia a fórmula tão freqüentemente citada (mas extraída de seu contexto) de Friedrich Julius Stahl: o Estado de direito "não representa em absoluto o objetivo e a substância do Estado, mas seu tipo e seu caráter" (STAHL, 1850, p. 137). Se, sobretudo para os governados, a maneira de governar é mais decisiva que a identidade dos governantes, abre-se a brecha para uma relativização da questão da soberania e de seu titular - o que consiste, evidentemente, em uma das características desta problemática de compromisso que será a teoria do Estado de direito.A firme rejeição por Kant de toda perspectiva revolucionária ${ }^{19}$ vai no mesmo sentido que o reformismo prudente dos liberais alemães durante o Vormärz, e mesmo depois.

A República kantiana é um Estado de direito? A despeito dos elementos já adiantados, certos de seus traços poderiam inclinar a pensar que não. Considere-se notadamente a recusa de todo direito de resistência, muito claro desde 1793 (KANT, 2003, p. 42 ss.), e sempre mais apoiado nos escritos ulteriores, em particular na Doutrina do direito. Todo ato de insubordinação remete à alta traição, mesmo se o governo age de maneira abusiva, pois qualquer resistência ao soberano legalmente constituído aniquila a "constituição legal", ou antes, o próprio "estado jurídico" (KANT, 2003b, p. 204 e 202). Convém contudo observar que a resistência proscrita reside naquela contra o soberano, a saber, contra o legislador e não contra o chefe do executivo, conquanto os exemplos aos quais 
Kant recorre (pensando, bem entendido, nos eventos que se produziram na ocasião da Revolução francesa) possam introduzir alguma confusão. Ora, esse poder "não pode pertencer senão à vontade unificada do povo" (KANT, 2003b, S 46, p. 196). Em acréscimo, Kant considera como aceitável uma constituição que permite ao povo resistir legalmente ao poder executivo, sob a forma da oposição parlamentar, à condição de que isso se restrinja a uma "resistência negativa", sem o que o povo "faria ele próprio ato de poder executivo" (KANT, 2003b, p. 204-205). Por conseguinte, a rejeição do direito de resistência ou sua restrição a um simples direito de reprimenda recobre uma opção reformista claramente fixada na Doutrina do direito. A recusa da revolução não deve então ser interpretada como o sinal de um tipo de crispação reacionária ou conservadora. Ela se explica primeiro porque a revolução é, com todo rigor, impensável. Não há e não pode haver nenhum direito de se opor ao direito em vigor, salvo em se negando a completude da ordem jurídica. Sobre esse ponto, ela se situa sobre a mesma linha que será adotada pelos teóricos do Estado de direito.

Aliás, não é duvidoso que a filosofia política de Kant prefigure sobre vários pontos importantes a problemática do Rechtsstaat. Pode-se assinalar três deles. Em primeiro lugar, a subordinação da política ao direito ou o ideal de juridificação da política. O Estado, como mais tarde em Kelsen, identifica-se à ordem jurídica, não é outra coisa que um rechtlicher Zustand. Reciprocamente, a propriedade caracterísitica do estado de natureza não se resume em ser um estado de injustiça, mas um "estado de ausência de direito", privado de uma administração pública deste por um "juiz competente" (KANT, 2003b, \44, p. 194). Como se vê, a abordagem kantiana do político tende a reduzi-lo inteiramente à sua dimensão jurídica. É preciso a esse respeito não se deixar deter por uma interpretação sumária dos apêndices do escrito sobre a paz perpétua, e em particular da famosa fórmula "a verdadeira política então não pode dar um passo antes de ter prestado homenagem à moral" (KANT, 1974, p. 155). É preciso com efeito lembrar que, no vocabulário kantiano, a moral é o gênero do qual o direito e a ética são as espécies ${ }^{20}$. Parece claro, a partir daí, que o cuidado de Kant, mesmo na Paz perpétua, não é o de moralizar a política, no sentido em que esta poderia e deveria unir a moralidade das disposições e a legalidade das ações, mas sim, como já se disse, o de juridificá-la. Também

doispontos, Curitiba, São Carlos, vol. 4, n. 1, p. 107-135, abril, 2007 
a fórmula supracitada pode ser assim traduzida: "o direito deve ser tido como sagrado para o homem, ainda que isso possa custar grandes sacrificios à potência que governa" (KANT, 1974, p. 155).

Segundo ponto sobre o qual Kant antecipa a doutrina do Rechtsstaat: salientam-se os princípios jurídicos formais, e não princípios materiais. Os dois traços distintivos da consituição republicana eram, como foi dito, a separação dos poderes e a existência de uma representação política (KANT, 1974, 1o. Art. definitivo, p. 95). Ora, eles concernem ao modo de governo $<$ Regierungsart $>$, não ao regime $<$ Staatsform $>$. Em outros termos, tais traços não impõem nenhuma determinação positiva dos fins do Estado nem de sua organização concreta, o que implica uma relativização da questão até então considerada central por toda filosofia política: aquela acerca do melhor regime. É verdade que os critérios formais do "Estado de direito" kantiano conduzem à rejeição da democracia pelo motivo de que ela seria "necessariamente um despotismo" (Ibid.). Mas não é em razão de seus caracteres substanciais que a soberania do povo é rejeitada - explicitamente, ao menos - mas pelas conseqüências que ela tem sobre o modo de exercício do poder, visto que a democracia (trata-se claro, como em todos os autores da época, da democracia "pura", como a nomeia O Federalista) compromete tanto o princípio da separação dos poderes quanto aquele da representação.

Terceiro e último ponto sobre o qual Kant prefigura a teoria do Estado de direito: ele admite a possibilidade, e mesmo a necessidade de uma autolimitação do Estado. Tal é, no fundo, o sentido positivo da proscrição de todo direito de resistência face ao chefe do executivo (regente) tanto quanto do legislador soberano. Ninguém além do soberano constituído tem o direito de fixar limites à ação do governo; mas é porque essa limitação é inerente às condições mesmas da sociedade política, e, em particular, porque ela resulta diretamente do "primeiro princípio" desta, a liberdade de todos.

\section{Hegel}

O Estado hegeliano - nada menos que o divino terrestre ${ }^{21}$ ! - pode pretender ser um Estado de direito? A questão, à primeira vista, parece 
bizarra, ao menos enquanto nos ativermos à imagem do hegelianismo firmemente estabelecida, não sem talento, por Rudolf Haym (HAYM, 1857, sobretudo a 15a lição: "Preussen und die Rechtsphilosophie", p. 357 ss.), e que permanece largamente dominante. Além disso, a Fenomenologia do espírito desenvolve uma análise impiedosa do que Hegel lá nomeia der Rechtszustand, o estado de direito ou a condição jurídica, em cuja descrição se reconhece, aliás sem dificuldade, certos traços característicos do império romano. Ele se caracteriza de um lado pela hegemonia formal de um direito privado minucioso - trata-se, claro, do direito romano em que reina uma "igualdade na qual todos, bem como igualmente cada um, valem como pessoas" (HEGEL, 1991, p. 325), e de outro pela dominação violenta de um "senhor do mundo", de uma "monstruosa consciência de si que se sabe como o deus efetivo" (HEGEL, 1991, p. 328). Equivale dizer que o reino de um formalismo jurídico igualitário não é de modo algum incompatível com a mais dura das tiranias, e que "o estado de direito" bem poderia ser apenas a roupagem de uma "violência destruidora" (Ibid.).

As coisas são todavia menos simples. Pode-se na realidade mostrar me esforcei para fazê-lo em um trabalho já antigo (KERVEGAN, 1987) - que a filosofia jurídica e política de Hegel, sem se inscrever na corrente que conduz às doutrinas do Rechtsstaat, antecipa não obstante suas reivindicações essenciais, embora propondo para elas um fundamento outro que aqueles que serão os mais freqüentemente invocados pelos "pais fundadores" (Robert von Mohl, Lorenz von Stein etc.). É o que se pode verificar, retomando sucessivamente alguns aspectos, se não da doutrina do Rechtsstaat no sentido técnico do termo - aliás ela só vê o dia bem ao fim da vida de Hegel -, ao menos das temáticas que ela irá aglutinar.

Em se tratando inicialmente da distribuição dos poderes do Estado, a corrente moderada professa, desde Montesquieu, que a liberdade política não poderia existir em um Estado se "toda a potência nele é única" (MONTESQUIEU, 1979, XI, vi, p. 295). Hegel, que habitualmente não é listado entre os representantes dessa corrente, considera todavia o princípio da divisão dos poderes como "um dos momentos absolutos da profundidade e da efetividade da liberdade" (HEGEL, 1988, \ 541 Obs., 1988 , p. 318); é o que provam a contrario o despotismo oriental de uma parte, a constituição democrática de outra, que uma e outra convêm 


\section{4}

nisso. Mas essa divisão $<$ Teilung $>$ deve ser entendida como uma diferenciação funcional do poder ou da potência do Estado, que é una em sua essência ou em seu conceito, e não como uma separação abstrata <Tren$n u n g>$. Esta, se fosse possível encará-la seriamente, comprometeria a unidade mesma da esfera política, e conduziria, na melhor das hipóteses, a um sistema de contrapesos, capaz no máximo de provocar um "equilíbrio universal", mas certamente não de engendrar uma "unidade viva" (HEGEL, 2003, \ 272, Obs., p. 365) 22. Na pior das hipóteses, a independência absoluta dos poderes, em particular do executivo e do legislativo, poderia culminar em um tipo de guerra civil silenciosa e, por aí, na "devastação do Estado" (Ibid.). Para evitar a aporia política à qual conduz uma visão cumulativa ou aditiva do Estado, Hegel trata os diversos poderes como aspectos parciais, unilaterais mas complementares, da unidade fundamental do Estado, à qual unicamente pertence propriamente a soberania:

"Os assuntos e os poderes particulares do Estado não têm subsistência por si, e solidez, nem por si nem na vontade particular dos indivíduos, mas têm ao contrário sua raiz última na unidade do Estado enquanto ela é seu si simples [ : ] a soberania do Estado constitui essas duas determinações" (HEGEL, 2003, \278, p. 374).

Assim como os momentos universal, particular et singular do conceito na Ciência da Lógica, à qual Hegel multiplica as referências quando ele expõe sua concepção da divisão dos poderes, cada um dos poderes do Estado, mesmo sendo material e formalmente distinto dos outros, é "ele próprio dentro de si a totalidade" (HEGEL, 2003, \ 272, p. 364): ele assume, em sua própria particularidade, a plenitude da potência estatal em sua totalidade e em sua unidade singular indecomponível.

É preciso também evocar brevemente as modificações que Hegel faz submeter à lista comumente admitida dos poderes do Estado. À distinção usual entre poder legislativo, executivo e judiciário, ele substitui aquela entre o poder legislativo (que representa o momento da universalidade), o poder governamental (momento da particularidade que inclui em si, como acontece em Fichte, a administração da justiça) e o poder principesco (que assume o ato da decisão política em sua irredutível singularidade). A absorção da justiça no vasto círculo das tarefas admi- 
nistrativas pertinentes ao "governo" pode surpreender e mesmo chocar. Mas, antes de ver nela a manifestação de uma vontade de subordinar a atividade jurisdicional ao poder político, é preciso lembrar que a divisão dos poderes é em Hegel rigorosamente funcional; ora, de um tal ponto de vista, não há lugar para separar administração e justiça, que são uma e outra - segundo o próprio Montesquieu - potências de execução, na ordem da particularidade empírica, da normatividade universal da lei. Aliás, deve-se ter presente no espírito o fato de que a administração do direito, embora tenha por agentes os funcionários do Estado, é para Hegel uma tarefa social antes que política, visto que sua destinação principal é a "proteção da propriedade" (HEGEL, 2003, \ 188, p. 284 ; cf. tb. \208, p. 298, et $\int 217$, p. 306); é aliás na seção consagrada ao estudo da sociedade civil (e não naquela que trata do Estado) que ela é estudada. Em um paralelo certamente intencional, ele apresenta o que nomeia a sociedade civil (noção que Hegel é o primeiro a utilizar em um sentido claramente diferente daquele, tradicional, da societas civilis sive politica) como organizada em torno de uma "constituição jurídica" < Rechtsverfassung $>$, exatamente como o Estado racional é estruturado pela constituição política < Staatsverfassung> (HEGEL, 2003, \ 157, p. 259). Donde uma suspeita que será o caso de testar: o estado de direito hegeliano (estado de direito no sentido de Rechtszustand e não de Rechtsstaat) supõe talvez menos o Estado propriamente dito, lugar da potência que a sociedade exerce sobre si própria e face a outras entidades políticas, que uma sociedade civil dotada de regulações econômicas (o mercado), jurídicas (a Rechtspflege) e institucionais (as "corporações" que organizam os ramos profissionais, as "profissões") que a tornam tendencialmente, mas não totalmente independente do Estado do qual ela se diferenciou do ponto de vista funcional. Para Hegel, partidário declarado das "idéias francesas" (mesmo se alhures ele critica sua abstração ; cf. HEGEL, 1977, p. 231) - quer dizer, como é sabido de todos, das idéias de 1789 -, "o Estado de direito" reside talvez antes de tudo no fato de que as relações entre indivíduos e grupos humanos não têm mais necessidade, ou não têm mais diretamente necessidade de ser geradas politicamente, como podia ser o caso em uma sociedade de ordens ou no que o costume alemão nomeia o Ständestaat.

doispontos, Curitiba, São Carlos, vol. 4, n. 1, p. 107-135, abril, 2007 
O segundo aspecto que é importante sublinhar é a maneira como a construção hegeliana assegura uma garantia institucionalizada dos direitos fundamentais, e em primeiro lugar aqueles que, de um ponto de vista estritamente liberal, são os únicos verdadeiramente fundamentais, a saber, os Freiheitsrechte, as liberdades nas quais se exprime e se verifica a liberdade "natural", quer dizer, não politicamente constituída, do homem individual. Que é feito desses direitos no Estado hegeliano? Em primeiro lugar, este último, enquanto expressão institucional da liberdade política - e no Estado moderno, a liberdade está à frente da igualdade (HEGEL, 1988, \ 539 Remarque, trad. III, p. 313-316) - reconhece e garante o que Hegel nomeia em um curso os "eternos direitos [dos] homens"23; a Declaração desses direitos constitui então um "catequismo elementar" (HEGEL, 1977, p. 240) que enuncia as bases - mas é preciso acrescentar: somente as bases - da organização do Estado ou da constituição. Todavia, na razão mesma de sua abstração, os direitos do homem, e mais particularmente os direitos de liberdade, que se definem antes de tudo como princípios de restrição do campo da ação política, não poderiam determinar o conteúdo de uma política efetiva. Ou então se tratará de uma política abstrata tal como a concebem e a conduzem os "homens de princípios" (HEGEL, 1977, p. 390) a partir do modelo dos revolucionários franceses, de uma política da virtude cujas formas e efeitos (pensa-se no Terror, bem entendido) não podem senão suscitar a inquietude.

De outro lado, e isto é sem dúvida ainda mais importante, Hegel não trata dos "direitos do homem" de uma maneira uniforme. Na esteira de Sieyès, "muito reputado por sua grande sagacidade na organização das constituições livres"24, Hegel opera uma diferenciação desses direitos. Mas dedica-se também a detectar as tensões, quiçá as contradições, que trabalham o bloco em aparência compacto que formam.

Em se tratando no início dos direitos de liberdade no sentido de Sieyès, portanto, dos "direitos de... ", Hegel avança duas coisas. De uma parte, esses direitos têm, como o conjunto dos princípios da ordem jurídica, "sua efetividade e sua garantia" na "potência estatal" (HEGEL, 1988, \544 Obs., p. 321), e eles encontram no espaço público (político) uma boa parte do seu domínio de exercício. É assim que, por exemplo, a liberdade de opinião e de expressão contribui, para o melhor ou para o pior, para a necessária regulação da vida política pelo debate e pela 
controvérsia e é por esta razão que "a opinião pública merece ser tanto respeitada quanto desprezada; desprezada quanto à sua consciência e à sua expressão exterior concretas, [mas] respeitada quanto a seu lugar essencial" (HEGEL, 2003, \318, p. 414). De outra parte, todavia, os direitos de liberdade - aqueles que proclama o artigo 2 da «Declaração dos direitos do Homem e do Cidadão » - são antes de tudo direitos não políticos e têm, enquanto direitos do homem, do homem em sua universalidade, seu campo concreto de atualização na sociedade civil. Entretanto, esta representa, no seio da totalidade ético-política, "o grau da diferença" (HEGEL, 2003, \ 181, p. 277) nisto : em separando os indivíduos uns dos outros, à medida que diversifica indefinidamente suas necessidades e seus desígnios, ela aparece, em relação à universalidade abstrata da família e da universalidade concreta do Estado, como o terreno da particularidade cindida, como o "sistema da atomística" (HEGEL, 1988, \523, trad. III, p. 303). Mas é precisamente porque ela é um operador muito poderoso de diferenciação dos indivíduos e dos grupos humanos que a sociedade civil moderna - e a sociedade civil é, por sua despolitização estrutural, essentialmente moderna - a uma só vez requer e dá um sentido eminentemente concreto ao princípio da igual liberdade que está no fundamento dos direitos do homem ${ }^{25}$; com efeito, ela despe o indivíduo, reduzido às funções de ator econômico e de pessoa jurídica, de todos os predicados estatutários de que a sociedade de ordens (e de privilégios) o investia, tornando assim possível o reino do formalismo jurídico que seu próprio funcionamento pressupõe. Assim, é em plena consciência das implicações que seu propósito comporta, notadamente no que concerne à questão dos "direitos do homem", que Hegel declara no início de sua análise do sistema das necessidades, quer dizer, da sociedade civil em sua dimensão mais estritamente econômica:

"É então aqui a primeira vez, e propriamente falando também a única, que está em questão nesse sentido o homem" (HEGEL, 2003, \ 190, Obs., p. 287)

Os direitos do homem, mas mais particularmente os direitos de liberdade, os direitos do homem em sua acepção propriamente liberal, são assim ligados, de uma maneira seguramente complexa, à existência e ao funcionamento de uma sociedade civil (burguesa) que o processo de 
autodiferenciação constitutivo da "modernidade" destacou da instituição propriamente política, isto é, do Estado. Daí que o titular verdadeiro desses direitos, seu "sujeito", não é nem o cidadão nem o sujeito moral: é o "Bürger no sentido de burguês" (HEGEL, 1972, p. 68), o homo oeconomicus ou ainda o homo socialis.

No que concerne agora aos direitos sociais, no sentido de Sieyès, eles se encontram claramente identificados e reconhecidos em Hegel, e é um ponto sobre o qual ele se afasta de uma perspectiva estritamente liberal, atenta, antes de tudo, em preservar o espaço da liberdade de cada um de qualquer ingerência do Estado. A exigência de que o direito não reine somente em geral, mas seja "efetivo na particularidade" implica com efeito que "o bem-estar particular seja tratado e efetuado como direito" (HEGEL, 2003, \ 230, p. 316). Sobre esse ponto, Hegel mostra-se muito menos "liberal" que Kant, o que confirma o tratamento muito atento que ele reserva à "questão social", que os $\int S 236$ e seguintes da Filosofia do Direito estudam a partir do exemplo da revolução industrial inglesa e de suas conseqüências: a constituição de um "populacho" e a desestabilização da própria sociedade civil, cujos modos normais de regulação (econômicos, jurídicos e sociais) não parecem mais em condição de funcionar de maneira conclusiva. Esta análise da pauperização como efeito estrutural do desenvolvimento da sociedade civil a partir de seu próprio princípio se conclui de maneira aporética pelo julgamento seguinte, bem distante da fé dos liberais na virtude do mercado:

"Aparece claramente (...) que, malgrado o excesso de fortuna, a sociedade civil não é suficientemente afortunada, quer dizer, ela não possui o suficiente, na riqueza de que ela está de posse, para remediar o excesso de pobreza e o engendramento do populacho" (HEGEL, 2003, \ 245, p. 324)

Mas, para voltar à questão dos "direitos sociais", Hegel sublinha dois pontos que, sem dúvida, dificilmente concordam com a perspectiva liberal na qual, para ser breve, se inscreve sua análise das liberdades. Em primeiro lugar, os direitos sociais, se eles supõem evidentemente a intervenção ativa e harmonizada da potência pública - é o ofício do que Hegel nomeia de maneira démodé a "polícia" -, têm na sociedade civil seu lugar autêntico e seu campo de exercício. Para retomar a distinção

doispontos, Curitiba, São Carlos, vol. 4, n. 1, p. 107-135, abril, 2007 
rousseauista e kantiana de que Hegel se apropria antes que ela seja dele retomada por Marx: os "direitos do homem em sociedade", como diz Sieyès, são direitos do "burguês" mais que do cidadão, do Bürger mais que do Staatsbürger26. Neste sentido deve-se interpretar a parte essencial consagrada às "corporações" (um outro termo antigo), quer dizer, as configurações institucionais que estruturam a sociedade civil e previnem o risco de sua redução a uma pura e simples sociedade de mercado; elas o podem sobretudo porque asseguram, conjuntamente com a administração (ou a polícia), a ligação constante dessa sociedade em que o universal não é senão o produto aleatório da concorrência dos interêsses particulares e do Estado que visa o interêsse geral, mas ao risco de mantêlo em uma abstrata oposição ao interêsse de todos. É então graças a essas instituições sociais e graças aos direitos cujo gôzo elas garantem a seus membros que a sociedade civil é sem dúvida, mas não é somente "o campo de batalha do interêsse privado individual de todos contra todos" (HEGEL, 2003, \ 289 Obs., p. 388).

Em segundo lugar, existe entre os direitos de liberdade e os direitos sociais, entre os "direitos de..." e os "direitos a..." uma contradição objetiva que demanda ser gerida politicamente. Na mesma medida em que é verdade que os direitos do homem são, em seu princípio mesmo, direitos não políticos (mas essa proposição tem, bem entendido, um sentido bem distinto daquele que ela podia ter em uma perspectiva jusnaturalista, visto que a idéia dos direitos originários ou naturais é para Hegel uma noção confusa ou contraditória), nesta mesma medida as tensões trabalhando o bloco que eles pretensamente formam - elas não fazem aliás senão refletir aquelas que afetam de maneira socialmente insuperável a sociedade civil - devem ser deixadas ao encargo da instituição política. Não que esta tenha por tarefa prioritária zelar pela "segurança e [pela] proteção da propriedade e da liberdade pessoal", o que significaria, em uma perspectiva que estaria em consonância com aquela do mais liberal dos teóricos do Rechtsstaat, que "o interêsse dos indivíduos singulares como tais é (...) o fim derradeiro em vista do qual eles estão reunidos" (HEGEL, 2003, \ 258 Obs., p. 334); senão se confundiria precisamente o Estado e a sociedade civil27. Mas somente a instância do universal real, instância que não tem outra localização possível que política (pois a universalidade que o direito garante e aquela que a economia política discerne no jogo contra- 
ditório dos interesses particulares são formais), somente a "garantia social", no sentido das Declarações francesas de 1789 e 1793 (quer dizer, a intervenção do Estado), está em condição de assegurar aos indivíduos e aos agrupamentos sociais mais ou menos estruturados o gôzo efetivo de direitos particulares mas antagônicos ${ }^{28} \mathrm{e}$ de tomar as decisões necessárias a um nivelamento das contradições que minam o pretenso bloco dos direitos do homem. Essas decisões, segundo Hegel, mais "liberal" nisso do que freqüentemente se diz, vão globalmente mais no sentido da liberdade (política e social) que naquele da igualdade. Ao menos elas deveriam ir nessa direção, pois Hegel está convencido - em oposição ao liberal que é Tocqueville - que as sociedades modernas tendem, malgrado certas aparências, mais à liberdade que à igualdade ${ }^{29}$.

Assim, a posição de Hegel com relação aos direitos do homem, longe de ser determinada por considerações políticas ou morais, é inteiramente comandada pela maneira inovadora como ele pensa a articulação complexa do Estado e da sociedade civil, do político e do jurídicoeconômico, nas condições da modernidade, quer dizer, no mundo surgido da Reforma protestante, da revolução política francesa e da revolução econômica inglesa. Sua convicção - que Marx retomará à sua maneira -, de que o controle das contradições da sociedade civil moderna não pode ser senão político o conduz a adotar uma posição que, indubitavelmente, não coincide com a perspectiva, liberal mas não "social" dos doutrinários do Rechtsstaat. A questão que se deve então colocar é a seguinte: é preciso situar Hegel antes ou depois da formação do campo de questionamento que deu origem às teorias do Estado de direito? De minha parte, eu considero que não há dúvida quanto à resposta: ela vem depois.

${ }^{1}$ Assim O mais antigo programa sistemático do idealismo alemão (se é que seu autor foi Schelling) e a primeira Nova dedução do direito natural, 1796.

2 Feuerbach, Jakob, Heydenreich, Hufeland, Scheidemantel, Schmalz e vários outros...

${ }^{3}$ Ver, por exemplo KRIEGEL, 1989, 1994.

4 Sem poder entrar no debate sobre a continuidade ou descontinuidade do pensamento fichteano, me contentarei aqui em dizer que os argumentos de Guéroult em favor daquela 
(GUEROULT, 1974) parecem-me consistentes e corroborados pelos textos, mesmo os mais "suspeitos", como os Discursos à nação alemã.

${ }^{5}$ Vê-se portanto que Fichte (assim como Kant) continua a identificar sociedade civil e Estado, mesmo quando ele estabelece a insuficiência de uma definição do vínculo social e termos exclusivamente políticos: eis por que, não obstante o uso, seria talvez oportuno, nesse contexto, traduzir bürgerliche Gesellschaft por "sociedade cívica", a fim de evitar qualquer confusão com a significação ulterior da expressão, tal como ela se depreende a partir de Hegel.

6 "Deve ser permitido a cada um retirar-se do centro para a circunferência, e mesmo sair do domínio do direito natural, se ele quer viver em uma ilha deserta" (FICHTE, 1989, p. 149).

7 Ibid. Lembremos que, para Locke, cuja influência as opções "radicais" do jovem Fichte freqüentemente traem, a obrigatoriedade do pacto social tem como contraparte o direito de emigração.

8 O "caráter fundamental da época" é "o fato de que, mais que nunca, o cidadão seja submetido com todas as suas forças ao Estado (...) e que o Estado procure tornar essa submissão universal e total" (FICHTE, p. 162-163).

9 De um lado, FICHTE, 2003, p. 49 ; de outro, FICHTE, 1984, p. 310, em que Fichte opõe "a desordem" própria a "nossos Estados de necessidade" ao Estado conforme à razão, em que "tudo está em ordem, tudo está regrado ".

10 É em particular o caso do dinheiro enquanto sinal: o Estado não tem nem mesmo que conhecer a importância da minha fortuna monetária, e ainda menos impô-la: o imposto, cuja finalidade é redistributiva (dar a cada um a possibilidade de subvencionar suas necessidades), concerne somente a produção dos bens de consumo.

11 Kant provocou um "avanço essencial" da teoria do Estado de direito (MOHL, 1855, I, p. 241). "[As] formulações de Kant ... contêm a expressão mais clara, definitiva, dos princípios da Aufklärung burguesa" (SCHMITT, 1993, p. 264).

${ }^{12}$ Ver KANT, 2003b, \45, p. 195, e 1973, p. 108. A respublica noumenon é a "norma eterna para toda constituição política <bürgerliche> em geral", e ela é "una e idêntica", enquanto que a respublica phaenomenon admite três formas, correspondendo aos tipos clássicos de constituição (Rx 8077,Ak., t. XIX, p. 610 ; trad. in CASTILLO, 1990, p. 288).

${ }^{13}$ Ver KANT, 2003, p. 30-38. As outras exposições, que comportam aliás variações não negligenciáveis, encontram-se em Paz perpétua (KANT, 1974, p. 91), e em Doutrina do direito (KANT, 2003b, \46, p. 196).

14 Essa distinção será retomada pela constituição "termidoriana" do ano III (1795).

15 KANT, 2003, p. 35. Os "cidadãos passivos" são, quanto a eles, rebatizados " protegidos" $<$ Schutzgenossen $>$.

16 Ver KANT, 2003b, Divisão Geral, p. 116, e \ 41, p. 188, em que o estado de natureza é caracterizado pela ausência de uma justiça distributiva.

17 KANT, 2003, p. 31. Ver Reflexão 7955 : "o que constitui o princípio de estabelecimento do Estado e sua idéia não é o princípio da felicidade universal, mas a liberdade segundo leis

doispontos, Curitiba, São Carlos, vol. 4, n. 1, p. 107-135, abril, 2007 


\section{2}

universais" (KANT, $A k$, t. XIX, p. 564).Ver também a Reflexão 8058 : "Não pode haver nada mais injusto que fazer da bondade o princípio do Estado ou do direito das gentes, visto que impõe-se a si mesmo como curador da felicidade dos outros e que se lhes retira a liberdade a fim de torná-los felizes segundo sua própria opinião" (KANT, $A k$, t. XIX, p. 610 ; trad. in CASTILLO, 1990, p. 282).

18 KANT, 1974, p. 95 . O texto alemão diz de maneira concisa que essa forma é uma Unform, uma "não-forma" de governo.

${ }^{19}$ Ver em particular a "Observação sobre os efeitos jurídicos que resultam da união civil", KANT, 2003b, p. 201ss., sobretudo p. 204-205.

${ }^{20}$ Ver a "Divisão da metafisica dos costumes", KANT, 2003b, p. $92-94$ e p. 115: Recht e Ethik são apresentados como os dois ramos da Moral.

21 "É preciso venerar o Estado como algo de divino" (HEGEL, 1974, vol. 3, p. 744 ; trata-se do curso de 1822-1823). Na própria Filosofia do direito, está dito da constituição que ela "deve ser considerada como o que é divino e persistente" (HEGEL, 1988, \ 274 Observação, p. 351).

22 A fórmula de Hegel evoca os checks and balances do Federalista (ver HAMILTON, MADISON \& JAY, 1988, artigos 9, p. 59, e 51, p. 428).

23 "[Em Roma] os escravos buscavam se liberar, alcançar o reconhecimento de seus eternos direitos de homens" (HEGEL, 1988, $₫ 433$ Adição, trad. III, p. 534).

${ }^{24}$ A única referência explícita que é feita a Sieyès nos escritos de Hegel figura em « Sobre o Reformbill inglês » (cf. (HEGEL, 1977, p. 385). Todavia, as alusões e as convergências são suficientemente numerosas para que se possa razoavelmente conjeturar que Hegel tem um certo conhecimento de seus escritos, dos quais uma importante seleção fôra traduzida em alemão (OELSNER, 1794).Ver PLANTY-BONJOUR, 1986, p. 13-35.

25 O caráter arquitetônico da "proposição de igualiberdade" na temática dos "direitos do homem" é perfeitamente colocado em evidência por BALIBAR, 1992 e 1997 p. 441 ss.

26 "Aqui [na sociedade civil] os Bürger são burgueses, não cidadãos; o indivíduo singular tem seu bem-estar por fim, ele é uma pessoa jurídica, o momento do direito emerge em uma universalidade" (HEGEL, 1983, p. 112-113) ; ver igualmente HEGEL, 2003, \$ 190, Obs., p. 287 ; HEGEL, 1972, p. 593. Sobre a significação geral dessa temática na obra de Hegel, ver minha contribuição : KERVEGAN, 1991, p. 279-301.

27 Hegel julga essa confusão teórica tão prejudicial que ele a denuncia por três vezes: ver 2003, $\$ 270$ Obs., p. 333; $\$ 270$ Obs., p. 360, e $\$ 324$ Obs., p. 420.

${ }^{28}$ Ver a maneira como Hegel analisa o exemplo a uma só vez antigo (cf. Aristóteles) e muito moderno do conflito de interêsses entre produtores e consumidores: (HEGEL, 2003, $\$ 236$, p. 318).

29 "Foi dito que os povos modernos eram capazes somente de igualdade, ou mais desta que da liberdade (...) É preciso dizer, ao contrário, que precisamente o alto desenvolvimento e aperfeiçoamento dos Estados modernos produz na efetividade a suprema desigualdade concreta dos indivíduos" (Hegel, 1988, $\$ 539$ Obs, III, p. 315).

doispontos, Curitiba, São Carlos, vol. 4, n. 1, p. 107-135, abril, 2007 


\section{Referências bibliográficas}

BALIBAR, E.1992. Les frontières de la démocratie, La Découverte. Paris

BALIBAR, E. 1997. "Les universels", in La crainte des masses, Galilée.

Paris

CASTILLO, M. 1990. Kant et l'avenir de la culture. Paris: PUF.

FICHTE, J. G. 2003. Conférences sur la destination du savant, 1794. Traduction et commentaire par J-L.Vieillard-Baron. Paris:Vrin.

FICHTE, J. G. 1989. Considérations sur la Révolution française. Paris: Payot.

FICHTE, J. G. 1984. Fondement du Droit naturel, trad. Renaut. Paris: PUF.

FICHTE, J. G. 1990. Le caractère de l'époque actuelle. (Introduction, traduction et notes par L. Radrizzani) Paris:Vrin.

FICHTE, J. G . 1986. Système de l'éthique. Paris: PUF.

GUEROULT, M. 1974. «Fichte et la Révolution française», in: Etudes sur Fichte, p. 152-246. Paris: Aubier-Montaigne.

HAYM, R. 1857. Hegel und seine Zeit, Berlin : R. Gaertner Verlag.

HAMILTON, A., MADISON J. \& J. JAY. 1988. Le Fédéraliste, trad. franc. G. Jèze, nova edição, Paris: Economica.

HEGEL, G. W. F. 1972. Leçons sur l'histoire de la philosophie, tome 3, Paris:Vrin.

HEGEL, G. W. F. 1988. Encyclopédie des Sciences philosophiques, t. 3: La philosophie de l'Esprit, trad. francesa B. Bourgeois, Vrin.

HEGEL, 1991. G. W. F. Phénoménologie de l'Esprit (trad. francesa : Lefebvre). Paris, Aubier.

HEGEL, G. W. F. 2003. Principes de la Philosophie du Droit. Paris: PUF.

HEGEL, G. W. F. 1977. Ecrits politiques. Paris: Champ Libre.

HEGEL, G. W. F. Des manières de traiter scientifiquement du droit naturel (trad. fr. B. Bourgeois) Paris:Vrin. 
134

HEGEL, G. W. F. 1974 Vorlesungen über Rechtsphilosophie (K-H. Ilting, ed.), Stuttgart-Bad Cannstatt (4 vol.).Vol. 3: Philosophie des Rechts.

HEGEL, G. W. F. 1983. Vorlesungen über Naturrecht und Staatswissenschaft, ed. Pöggeler, Meiner.

JOUANJAN, O. 1998. «Etat de droit, forme de gouvernement et représentation. A partir d'un passage de Kant», in: Annales de la Faculté de Droit de Strasbourg, Nouvelle série, $\mathrm{n}^{\circ}$ 2: Etudes de droit théorique et pratique, PUS.

KANT, I. 2003. Théorie et pratique - Sur um pretendu droit de mentir par humanité. Paris: Vrin.

KANT, I. 1974. Vers la paix perpétuelle. Paris: PUF.

KANT, I. 2003b. Doctrine du Droit. Paris:Vrin.

KANT, I. 1973. Le conflit des facultés. Paris:Vrin.

KERVEGAN, J-F. 1987. «Hegel et l'Etat de droit», Archives de Philosophie, 50-1, p. 55-94.

KERVEGAN, J-F. 1991. "Le citoyen contre le bourgeois. Le jeune Hegel et la quête de l'esprit du tout", in H.-F. Fulda et R.-P. Horstmann (org.). Rousseau, die Revolution und der junge Hegel, Stuttgart: Klett-Cotta.

KRIEGEL, 1989 Les droits de l'homme et le droit naturel, Paris: PUF.

KRIEGEL, 1994. Les chemins de l'État, Paris. Calmann-Lévy.

LEON, X. 1922. Fichte et son temps. Paris: Armand Colin.

MOHL, R.V. 1855. Geschichte und Literatur der Staatswissenschaften. Bd. I. Erlangen, F. Enke.

MONTESQUIEU, 1979. De l'esprit des Lois. Paris: GarnierFlammarion.

OELSNER, C. E. 1794. Emmanuel Sieyès politische Schriften, vollständig gesammelt von dem deutschen Übersetzer.

doispontos, Curitiba, São Carlos, vol. 4, n. 1, p. 107-135, abril, 2007 
PLANTY-BONJOUR, G. 1986. "Du régime représentatif selon Sieyès à la monarchie constitutionnelle selon Hegel", in H.-C. Lucas et O. Pöggeler (orgs.) Hegels Rechtsphilosophie im Zusammenhang der europäischen Verfassungsgeschichte. Frommann-Holzboog, p. 13-35.

SCHMITT, C. 1993. Théorie de la Constitution. Paris: PUF.

SIEYÈS, E. J. 1988. "Reconnaissance et exposition raisonnée des droits de l'homme et du citoyen" (julho de 1789), in: La Déclaration des droits de l'homme et du citoyen, ed. Rials, Hachette.

STAHL, F-J. 1850. Philosophie des Rechts, Band II: Staats- und Rechtslehre, Berlin 
136 